\title{
EI desafío de las artistas contemporáneas. Una aproximación a la presencia de las creadoras en las ferias de arte contemporáneo. El caso de ARCO.
}

\author{
Yolanda BETETA MARTÍN \\ Universidad Complutense de Madrid \\ yolandabeteta@ucm.es
}

Recibido: 05.09.2013

Aceptado: 25.11.2013

\begin{abstract}
RESUMEN
El artículo analiza la presencia de las mujeres artistas en la feria de arte contemporáneo ARCO. Desde su primera edición se ha incrementado progresivamente el número de mujeres artistas que participan en la feria. No obstante, el número de creadoras es notablemente inferior al de artistas masculinos. El artículo expone los datos de representación de las artistas desde la primera edición de ARCO en 1982 hasta el año 2012 con el objeto de valorar el impacto de las políticas de igualdad en las ferias del arte contemporáneo.
\end{abstract}

Palabras clave: Mujeres, Arte Contemporáneo, ARCO, Ferias de arte.

The challenge of the modern women artists.

An approach to the presence of women in contemporary art fair. The case of ARCO.

\begin{abstract}
The purpose of this research is to analyze the presence of women artists at the Modern Art Fair ARCO. The number of women artist has gradually increased from the first edition thirty years ago. However, the presence of women is significantly lower than male artists. The research displays the data representation of women artists from the first edition of ARCO in 1982 to 2012 in order to assess the impact of equality policies in contemporary art fairs.
\end{abstract}

Keywords: Women, Modern Art, ARCO, Art Fairs. 


\section{LAS GUERRILLA GIRLS, LAS POLÍticAs PÚBLICAS Y LA REDEFINICIÓN DE LA EPISTEMOLOGÍA MUSEÍSTICA.}

Durante la celebración de la feria de arte contemporáneo ARCO 2013 se presentó la II Edición del Festival "Mirada de Mujeres"1. El festival, que nació en el año 2012, surgió como un espacio cultural, crítico y reivindicativo que cuestiona la invisibilidad de las mujeres en el mundo del arte en todas sus vertientes (gestión, distribución y creación) y propone una programación de exposiciones y actividades diseñadas y/o protagonizadas por mujeres artistas, críticas de arte, comisarias e investigadoras que arrojen luz sobre la estrecha relación entre mujeres, arte y creación.

La presentación de la II Edición del Festival durante la celebración de ARCO 2013, una de las ferias de arte contemporáneo más reconocida del circuito internacional, no es una decisión tomada al azar. El espacio en el que se desarrolló la presentación reforzó la razón de ser del propio festival debido a la acusada desigualdad de género que muestra la oferta artística de ARCO. Del conjunto de obras de arte que anualmente se exhiben en esta feria internacional de arte ni siquiera una tercera parte son obras creadas por mujeres.

Esta falta de representatividad de las artistas en las ferias de arte no sólo es injusta en términos sociales sino que, además, vulnera el marco jurídico que establece la Ley Orgánica 3/2007 de 22 de marzo, para la igualdad efectiva de mujeres y hombres que en su artículo 26 señala que "las autoridades públicas, en el ámbito de sus competencias, velarán por hacer efectivo el principio de igualdad de trato y de oportunidades entre mujeres y hombres en todo lo concerniente a la creación y producción artística e intelectual y a la difusión de la misma"2.

Dicha ley propone a los distintos organismos, agencias y administraciones públicas que gestionan el patrimonio cultural de un modo directo o indirecto el desarrollo de las siguientes actuaciones para garantizar la igualdad en la creación y difusión intelectual y artística: adoptar iniciativas destinadas a favorecer la promoción específica de las mujeres en la cultura y a combatir su discriminación estructural, elaborar políticas activas de ayuda a la creación y producción artística e intelectual de las mujeres con el objeto de crear las condiciones para que se favorezca la efectiva igualdad de oportunidades, promover la presencia equilibrada de mujeres y hombres en la oferta artística y cultural pública, que se respete y se garantice la representación equilibrada en los distintos órganos consultivos, científicos y de decisión existentes en el organigrama artístico y cultural, adoptar

1 http://www.festivalmiradasdemujeres.com/

$2\urcorner$ BOE-A-2007-6115: http://www.boe.es/buscar/doc.php?id=BOE-A-2007-6115 
medidas de acción positiva a la creación y producción artística e intelectual de las mujeres propiciando el intercambio cultural, intelectual y artístico y la suscripción de convenios con los organismos competentes.

Sin embargo, estas directrices políticas aún no se han implantado de manera generalizada en los museos, galerías y ferias de arte. Las mujeres que acuden a estos espacios artísticos como espectadoras o como artistas encuentran numerosas dificultades para reconocerse así mismas en la memoria histórica y son testigos de la prevalencia de unos roles de género que sistemáticamente las excluye de la cultura. Pese a que las aportaciones artísticas de las mujeres han adquirido una mayor importancia en las colecciones museísticas y se han impulsado diversos proyectos de reivindicación de la autoría femenina desde diversos ámbitos de conocimiento, lo cierto es que los museos, galerías y ferias de arte aún mantienen unos estereotipos culturales sexistas.

Pese a que no existe un estudio completo sobre la presencia de las mujeres en los ámbitos artísticos y museísticos, algunas investigaciones subrayan el profundo desequilibrio que existe en la representación y reconocimiento de los artistas en función de su sexo ${ }^{3}$. De los quince Premios Nacionales de Artes Plásticas convocados desde 1994 sólo tres de ellos se han concedido a mujeres artistas: Eva Lootz (1994), Cristina Iglesias (1996) y Esther Ferrer (2008). La misma cifra se desprende de las Premios Nacionales de Fotografía que sólo ha reconocido el trabajo de Cristina García Rodero (1996), Ouka Lele (2005) y María Bleda (2008). El Premio Velázquez de Artes Plásticas convocado anualmente desde el año 2002 sólo ha otorgado un galardón a una mujer artista, Dolores Salcedo (2008), y de los Premios Príncipe de Asturias de las Artes ninguno ha recaído en una mujer. ${ }^{4}$

Lo sorprendente de los datos no es sólo el poco calado que las políticas de igualdad tienen en el ámbito de la difusión y reconocimiento de una cultura igualitaria sino en la naturalidad con la que se asume la presunta ausencia de las mujeres de la cultura. Las mujeres padecen una doble discriminación: sus creaciones son invisibilizadas en los espacios públicos y dichas ausencias a su vez resultan invisibles. La exclusión de las mujeres en la creación artística está tan naturalizada en el inconsciente colectivo que poca gente repara en ella. Por tanto,

3 Una de las iniciativas para analizar y promover la igualdad de género en los museos es el proyecto I+D+i FEM 2010-16670 "Estudio de los fondos museísticos desde la perspectiva de género: Museo del Prado, Museo Nacional Centro de Arte Reina Sofía, Museo Arqueológico Nacional y Museo del Traje" dirigido por la Dra. Marián López Fdez Cao y fruto de un convenio de colaboración entre el Instituto de Investigaciones Feministas de la UCM, el Ministerio de Cultura y los museos públicos implicados en el proyecto.

4 Datos disponibles en la página web del Ministerio de Cultura: http://www.mcu.es/premios/Indice.html 
es necesario deconstruir la museología clásica y el canon artístico tradicional e incorporar una perspectiva de género que permita que las mujeres puedan reconocerse en el pasado histórico y en el presente de la colectividad.

La deconstrucción de la epistemología museística y del canon artístico es un proceso complejo que involucra a diversos agentes culturales, sociales y políticos. No es una labor que los museos, galerías y ferias de puedan realizar en solitario. La revisión crítica de la gestión del arte exige una deconstrucción paralela de la historia de las artes, las ciencias y las humanidades. Una redefinición de los saberes científicos que requiere nuevos elementos conceptuales, metodológicos y pedagógicos que permitan la creación de espacios de análisis y reflexión crítica acerca de la discriminación de las mujeres en la historiografía de las artes y las letras. Una revisión epistemológica que permita desaprender lo aprendido para revisarlo desde una perspectiva feminista y que aglutine a todos los actores sociales, políticos y educativos para redefinir el sistema del arte a medio y largo plazo.

Han pasado veinticuatro años desde que el colectivo de artistas feministas Guerrilla Girls denunciara la discriminación de las mujeres en el sistema del arte al plantear una cuestión que revolucionó los cimientos de la Historia del arte y de la crítica artística: "¿Tienen las mujeres que estar desnudas para entrar en el Metropolitan Museum?". Las Guerrilla Girls cuestionaban así que menos del 5\% de los artistas que integraban la colección de las secciones de Arte Moderno de dicho museo eran mujeres ${ }^{5}$.

Los planteamientos y objetivos de las Guerrilla Girls inspiran este artículo que recoge la pregunta que lanzaron en 1989 a los responsables del Metropolitan Museum de Nueva York para extrapolarla a la situación de los centros y ferias de arte. El objetivo del artículo es analizar si 24 años después de la actuación de las Guerrillas Girls ante las puertas el Met de Nueva York y tras la promulgación de iniciativas legislativas basadas en el principio de igualdad entre mujeres y hombres se ha producido una transformación en las políticas de adquisición y difusión de obras de arte en las centros de arte contemporáneo.

La hipótesis de partida es que la perspectiva de género, que implica el coprotagonismo de las mujeres en la construcción de la cultura y la memoria

5 Las Guerrilla Girls es un colectivo de artistas feministas. El grupo nació en Nueva York en 1984 para denunciar la discriminación que padecen las mujeres en el mundo del arte mediante el uso de tácticas de guerrilla. Su primer acto de reivindicación fue la celebración de una manifestación ante el MOMA de Nueva York ataviadas con máscaras de simios para denunciar la escasa representación de las mujeres artistas en la colección del museo. A lo largo de los años, han ampliado su activismo a la industria del cine, la cultura popular, los derechos civiles y la discriminación racial. Más información en la página web del colectivo: http://www.guerrillagirls.com/ 
histórica, está ausente de las ferias de arte contemporáneo. Sin embargo, es posible una reestructuración de los fondos, de los discursos expositivos y de las políticas culturales museográficas, que posibiliten la inclusión del punto de vista de las mujeres, su protagonismo como protagonistas de la Historia y la cultura. La realización del estudio se justifica por el reconocimiento que las políticas europeas han otorgado a la necesidad de transformar los discursos museísticos desde una perspectiva de género y, en especial, el Séptimo Programa Marco de la Comisión Europea (2007-2013) que señala la necesidad de visibilizar a las mujeres en los museos y centros de arte como una estrategia necesaria en el desarrollo social, cultural y económico europeo.

\section{UNA APROXIMACIÓN A LA PARTICIPACIÓN DE LAS ARTISTAS EN LAS FERIAS DE ARTE CONTEMPORÁNEO. ARCO.}

La escasa representación de las mujeres en las instituciones museísticas, galerías y ferias de arte ha sido denunciada de manera recurrente en las últimas décadas desde distintos foros universitarios y asociaciones artísticas. Los recientes informes de la Asociación de Mujeres en las Artes Visuales (MAV) ${ }^{6}$ indican que la presencia de las mujeres artistas en los centros de arte españoles durante la última década es inferior al $10 \%{ }^{7}$. Esta situación se repite en ARCO. En sus últimas ediciones se observa un incremento del número de obras creadas por mujeres, sin embargo, los datos de representación femenina siguen siendo extremadamente bajos.

El galerista Luis Adelantado, que cuenta en su galería con artistas como Sophie Calle, Chantal Anckerman, Pipilotti Rist, Montse Soto o Carmen Calvo, confirma las dificultades de las mujeres artistas en el día a día de una galería de arte. "No sé qué pasa, pero siempre he trabajado con muchas mujeres que están una temporada y después parece que se diluyen" ${ }^{8}$. Luis Adelantado confirma la existencia de sólidos perjuicios en la mente de los potenciales compradores de arte. "Lo que sí hay es algunos coleccionistas que, de manera anecdótica, dicen que prefieren no comprar mujeres porque a largo plazo esa obra no tendrá la duración y firmeza del inicio ya que cuando tienen hijos la carrera se ralentiza" ${ }^{9}$. Una situación que se agrava en la actual situación de crisis estructural en la que los compradores no

$6 \mathrm{MAV}$. http://www.mav.org.es/

7 Informe $n^{\circ} 5$ de MAV. Exposiciones individuales en 22 centros de arte en España (1999 2009). Enero 2011.

8 Declaraciones publicadas en el diario EL País el 20 de febrero de 2011. http:/cultura.elpais.com/cultura/2011/02/20/actualidad/1298156401 850215.html

9 Ibid. 
arriesgan a la hora de invertir en la compra de obras de arte. El arte masculino, a día de hoy, se continúa percibiendo como un valor más seguro.

Marta Gili, actual directora del Jeu de Paume de París, llama la atención sobre el hecho de que las piezas de Esther Ferrer, "una artista que si hubiera sido hombre seguro que tendría mucho más relevancia" ${ }^{10}$, salgan al mercado del arte con un precio muy por debajo de su calidad y proyección artística. Lo cierto es que esta situación se repite en todos los casos de mujeres artistas como vuelve a apuntar Marta Gili: "A la gran Louise Bourgeois no se le dedicó una gran exposición monográfica en París hasta hace tres años y lo mismo pasa con otras artistas"11.

La preocupación por la baja participación de las mujeres en los procesos de creación, gestión y difusión del arte contemporáneo se ha hecho muy visible en la última década a partir, fundamentalmente, de la publicación de un manifiesto en el que se denunciaba la reducida presencia de mujeres artistas en las programaciones y eventos internacionales sufragados con dinero público. El manifiesto, firmado por profesionales del sistema del arte, y publicado paralelamente a la inauguración de ARCO 2005, denunciaba lo siguiente:

"En el Museo Nacional Centro de Arte Reina Sofía de las veintiocho exposiciones programadas en 2004 solamente cuatro eran de artistas mujeres [...]. Las dos exposiciones que el Ministerio de Asuntos Exteriores patrocinó para representar a España en la Bienal de Venecia 2003 no incluían a ninguna artista. Gaur, Hemen, Orain, la exposición que en 2002 en el Museo de Bellas Artes de Bilbao pretendía mostrar la nueva escena del arte vasco contaba con veinte artistas de las cuales únicamente cinco eran mujeres. En Manifesta 5, la Bienal de Arte Contemporáneo Europea que en su última edición se ha desarrollado en San Sebastián y pretende mostrar el arte de mayor interés generado en los dos últimos años, la representación de las artistas no superaba el 20\%",12.

Estos datos de representación han sido respaldados por los informes de la asociación Mujeres en las Artes Visuales. Los datos de los informes de MAV señalan que la escasa participación de las mujeres en las actividades de difusión artística (exposiciones, colecciones permanentes y retrospectivas) impulsadas por las instituciones museísticas españolas no se corresponde con la notable presencia de mujeres en los cargos de gestión del sistema artístico español. El Informe MAV $\mathrm{N}^{\mathrm{o}} 6$ señala que mientras las galerías de arte dirigidas por mujeres constituyen el

107 Entrevista publicada en el diario EL País el 20 de febrero de 2011. http://cultura.elpais.com/cultura/2011/02/20/actualidad/1298156401 850215.html

11 Ibid.

12 "Manifiesto. Las políticas de igualdad entre hombres y mujeres en los mundos del arte", ARCO. Arte Contemporáneo. ARCO Especial. Mirada retrospectiva, 2005, p. 200. 
$34,3 \%$ del total de galerías españolas analizadas en el año 2011, sólo el $24,7 \%$ de las obras exhibidas en ellas son creaciones de mujeres artistas ${ }^{13}$.

El balance de los estudios sobre datos de representación en el sistema de las artes es claramente discriminatorio para las mujeres especialmente en las esferas de la creación y difusión artística. La periodista Ángeles López declaró que "el mundo del arte admite con los brazos abiertos a las mujeres que dirigen instituciones tan relevantes como la Biblioteca Nacional o el Reina Sofía. Sin embargo, escritoras, intérpretes, pintoras y arquitectas están relegadas a un segundo plano respecto a sus colegas varones" ${ }^{, 14}$.

ARCO reproduce la misma tendencia observada en la mayoría de los museos españoles ${ }^{15}$. La historia y evolución de ARCO han transcurrido de forma paralela al fortalecimiento del sector cultural y del arte contemporáneo en España durante el periodo democrático. En este sentido, la feria ha sido una pieza clave para la generación e impulso de las galerías de arte y del fomento coleccionismo tanto privado como institucional y corporativo. Hoy, además de ser un evento masivo, se ha convertido en la herramienta fundamental para la difusión, promoción y gestión del arte en España donde se dan cita galeristas, comisarios/as, directores/as de museos, coleccionistas, artistas, instituciones y fundaciones.

El análisis de la presencia de mujeres artistas en ARCO se ha realizado a partir de los datos proporcionados por la organización de la feria en sus catálogos anuales. La metodología de investigación ha sido cuantitativa y se han tomado como referencia los datos de los años 1982, 1988, 1994, 2000, 2006 y 2012. El desglose de los datos se ha realizado en tramos de seis años para obtener una visión global y progresiva de la presencia/ausencia de las mujeres a medida que se implementaban las políticas de igualdad desde los organismos públicos nacionales e internacionales.

La participación de las mujeres artistas en las exposiciones de ARCO se ha incrementado de forma notable y progresiva desde la primera feria de arte organizada en el año 1982 (gráfico 1). En ese año el nivel de participación de mujeres sólo alcanzó el $6,60 \%$ del total de artistas que formaron parte de la feria.

13

Informe

MAV

$\mathrm{N}^{\mathrm{o}}$

6

(mayo

2011).

http://www.mav.org.es/index.php/observatorio/informes/508-informe-mav-n6

14 Informe "La mujer en España. Cultura" (YO DONA, julio de 2007).

$15^{7}$ Para una aproximación a la presencia de las mujeres en los museos públicos españoles consúltese: LÓPEZ CAO, M., FERNÁNDEZ, A. y BERNÁRDEZ, A. (2012): El protagonismo de las mujeres en los museos, Fundamentos. Madrid. 
Desde ese año se ha producido un ascenso del número de mujeres artistas participantes hasta llegar a un porcentaje del $31 \%$ en el año 2012.

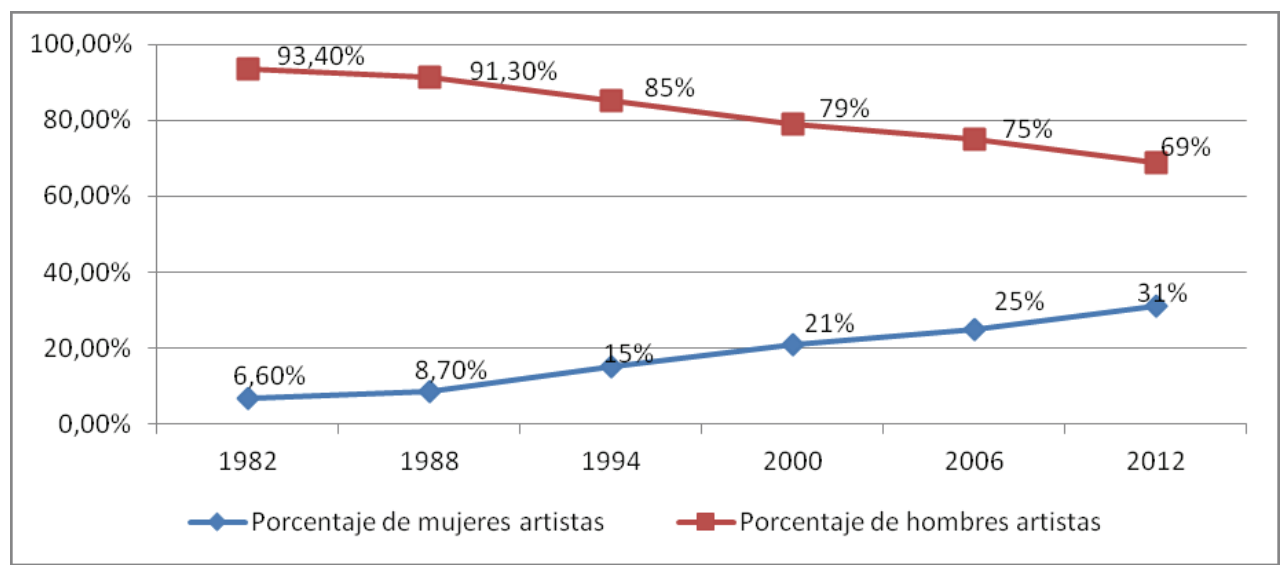

Gráfico 1. Evolución porcentual de la presencia de mujeres artistas en ARCO entre los años 1982 y 2012.

Fuente: Catálogos de ARCO.

Durante la década de los años '80 el incremento de las mujeres artistas en ARCO fue muy lento ya que si comparamos los datos de representación de los años 1982 y 1988 únicamente se registra un aumento del 2,10\%. En los años '90 se produce una mejoría notable y las artistas logran alcanzar un $15 \%$ del total en el año 1994. Sin embargo, es en la década de 2000 cuando las mujeres consiguen superar una cuarta parte de la representación (año 2006) hasta llegar el 31\% en la feria celebrada en el 2012.

La comparación de los datos del año 1982 y 2012 muestra claramente el incremento de las presencias de las mujeres en ARCO (gráfico 2). Dicho aumento ha sido lento e insuficiente en la medida en que las mujeres aún no alcanzan el $50 \%$ del total de artistas. No obstante, las políticas de difusión de artistas de ARCO son similares a la desarrolladas por la mayoría de ferias y museos de arte contemporáneo. 


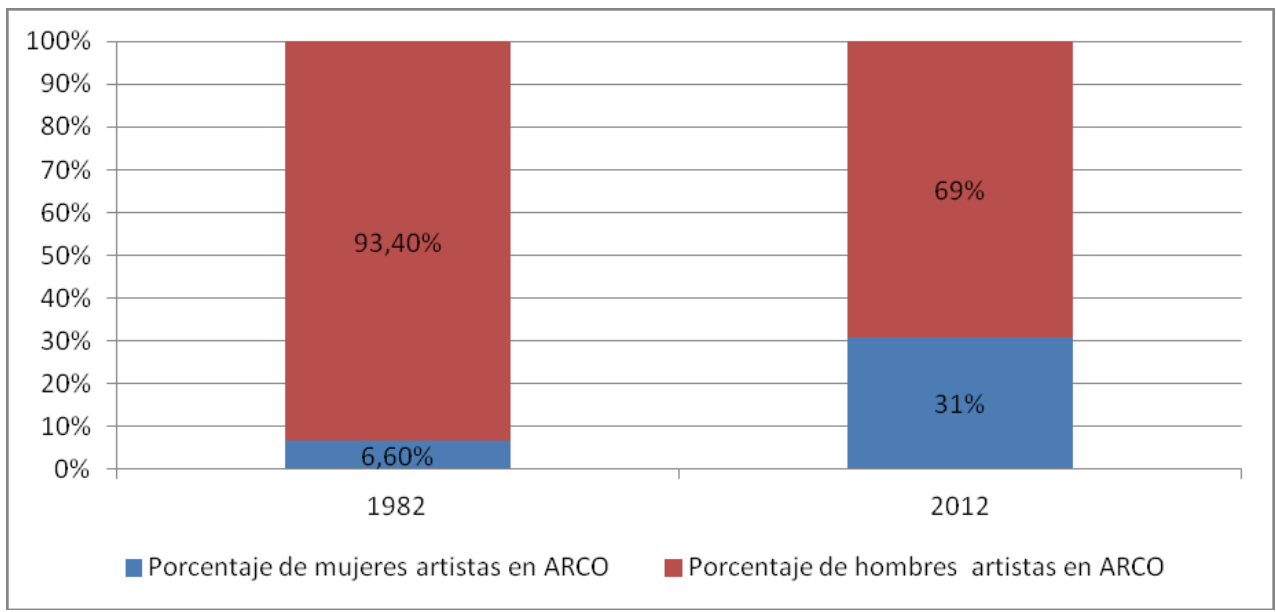

Gráfico 2. Comparativa del porcentaje de mujeres artistas en ARCO en los años 1982 y 2012.

Fuente: Catálogos de ARCO.

La evolución del Museo Nacional Centro de Arte Reina Sofía (en adelante MNCARS) muestra una tendencia similar a la detectada en ARCO (gráfico 3). La elección del MNCARS como ejemplo de museo de arte moderno responde a su importancia como centro de arte y a su compromiso con las políticas de igualdad de género plasmada en el itinerario Feminismo. Una mirada feminista sobre las vanguardias ${ }^{16}$. Los datos de la representación de mujeres artistas en ARCO y del número de exposiciones del MNCARS dedicadas exclusivamente a mujeres en el año manifiestan unos índices de participación similares. La presencia de creadoras en ARCO 2012 fue de un 31\% del total de artistas mientras que el MNCARS organizó tres exposiciones dedicadas íntegramente a mujeres artistas en ese mismo años lo que supone un $37,5 \%$ del total.

$16^{7}$ Itinerario alternativo que subraya la importancia de las mujeres en la Historia del Arte a través de una selección de obras que integran la Colección 1 del museo. El itinerario, diseñado por el Instituto de Investigaciones Feministas de la UCM en colaboración con el MNCARS y enmarcado en el proyecto de investigación FEM 2010-16670 dirigido por la Dra. Marián López Fdez Cao, se encuentra disponible on line en la siguiente página web: http://www.museosenfemenino.es/ 


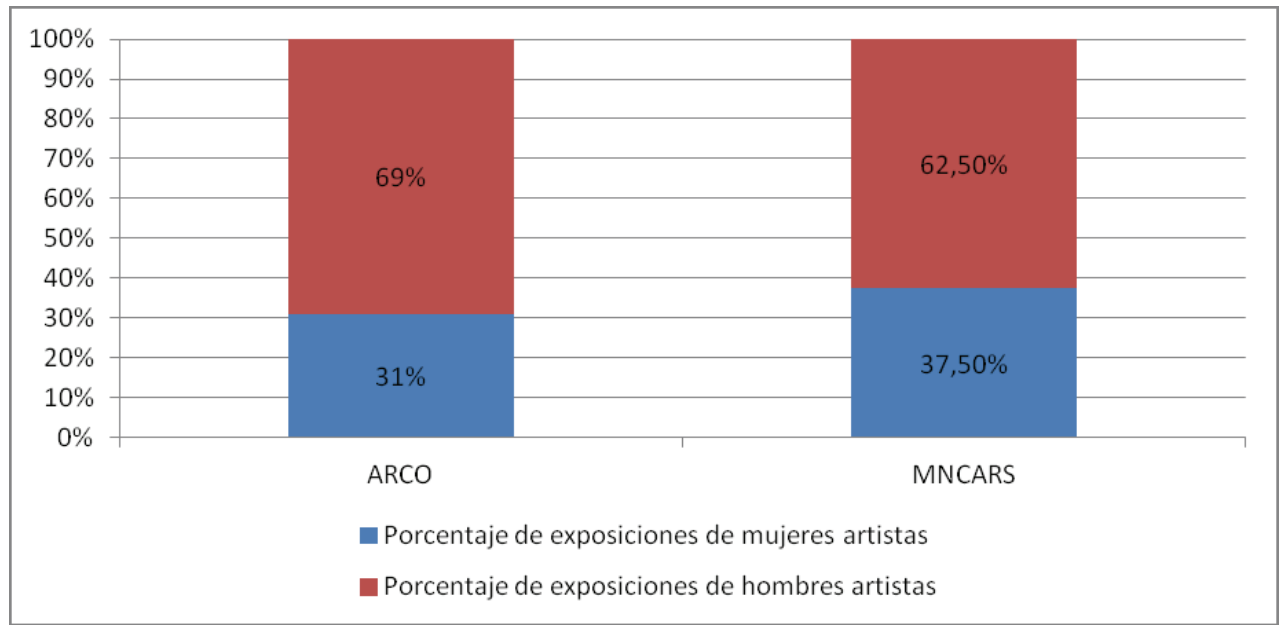

Gráfico 3. Datos porcentuales de las exposiciones individuales desagregadas por sexo del MNCARS y de ARCO en el año 2012.

Fuente: Catálogos de ARCO y Base de datos del MNCARS.

La visibilidad de las creadoras en ARCO se ha incrementado de manera progresiva en los últimos treinta años sin que se haya producido un descenso o retroceso en dicho avance. Es difícil valorar si las iniciativas legislativas en materia de igualdad han influido en las políticas de gestión y difusión de ARCO. Sí se puede afirmar que en la década del 2000 se produce un mayor aumento del número de mujeres artistas en la feria internacional coincidiendo con la aprobación de la Ley Orgánica 3/2007 de 22 de marzo, para la igualdad efectiva de mujeres y hombres, que en su artículo 26 señala que las autoridades públicas velarán por hacer efectivo el principio de igualdad de trato y de oportunidades entre mujeres y hombres en todo lo concerniente a la creación y producción artística e intelectual y a la difusión de la misma.

Los datos de los/as artistas que formaron parte de la edición ARCO 2013 no habían sido publicados cuando se llevó a cabo la presente investigación. No obstante, y a falta de los datos cuantitativos, un recorrido por la feria permitió observar la innovadora contribución de las mujeres artistas. La presencia de Esther Ferrer y Elena Asins encabezó la participación de creadoras con una sólida trayectoria artística; nombre imprescindibles en una edición en la que los recortes presupuestarios llevaron a organizar una feria marcada por los valores seguros y el coleccionismo más riguroso.

No obstante, las mujeres artistas lograron abrirse paso en medio de durísimas restricciones económicas. Destaco especialmente a aquellas mujeres que han 
participado en ARCO 2013 situando el espacio femenino en el centro de su creación artística. Las obras de la joven artista alemana Iris Schomaker reflexionan sobre todo en la especificidad de los mundos y espacios femeninos evocados no tanto en sus figuras como en el modo en que éstas ocupan el entrono mezclando vida y silencio. Zaha Hadid concitó entusiasmos con una obra que reunía diversos fragmentos de las maquetas de algunos de sus proyectos arquitectónicos. Pero hubo una propuesta más silenciosa e inspiradora a mi parecer: la de Carme Nogueira que estudia los desplazamientos que ocurren en las ciudades a lo largo del tiempo y en los que se alteran los núcleos de habitación con los centros de decisión; espacios de feminidad y espacios de masculinidad en los que se imbrica la memoria y la palabra. Esta iniciativa es similar a la obra de Françoise Vanneraud que ha rastreado el barrio madrileño de Tetuán para recuperar el modo de vida de los años cincuenta, y sobre todo, guarda relación con los trabajos de Daniela Ortiz, que estudia el espacio que la arquitectura urbana moderna concede a las mujeres empleadas en el hogar.

La reivindicación de los espacios femeninos ha marcado sin duda la última edición de ARCO; una feria en la que, a falta de datos cuantitativos, ha mantenido la tendencia observada a lo largo de su historia: la infrarrepresentación de las mujeres artistas. No es posible realizar una proyección del camino que adoptará ARCO en sus próximas ediciones. Sí se ha hecho público que Finlandia, país impulsor de una mayor implicación de las mujeres en la esfera pública, será el país invitado en la edición del 2014. ¿Finlandia será capaz de romper la tendencia de ARCO? El comisario finlandés, Leevi Haapala, director del museo Kiasma de Helsinki, subrayó que las mujeres estarian ampliamente representadas. Una afirmación lógica si se tiene en cuenta que el $43 \%$ de los mejores artistas finlandeses son mujeres a diferencia del $13 \%$ mundial ${ }^{17}$. Tal vez el motor de cambio provenga de los países invitados que en los últimos años han dado especial protagonismo a las obras de jóvenes artistas, mujeres en su mayoría, como ya se observó en FOCUS Turquía de la edición ARCO 2013.

\section{EL DESAFÍO DE LAS CREADORAS DE ARTE CONTEMPORÁNEO: VISIBILIDAD Y RECONOCIMIENTO.}

En el último año el mundo del arte ha recibido la noticia de la muerte de dos artistas. La desaparición de Mike Kelley a sus 57 años ha dado la vuelta al mundo. La segunda, la de Dorothea Tanning con 101 años, última superviviente del movimiento surrealista, ha tenido menor eco. Se podría argumentar que la muerte

17 Informe anual de la Fundación Kiasma, 2013. 
de una persona mayor no resulta tan impactante como la de alguien más joven fallecida además en circunstancias poco claras. Sin embargo, esta afirmación también podría ser una forma de justificar una realidad diferente. Quizás Tanning, como ocurre a menudo con las mujeres artistas era, sencillamente, menos visible. ¿Cuántas páginas habría dedicado la prensa internacional a Dorothea Tanning si hubiera sido un creador en lugar de una creadora?

Pese al escaso impacto de la noticia, la norteamericana Tanning fue un mito dentro del Surrealismo. Casada con Max Ernst y amiga de Man Ray, Dorothea Tanning usó la pintura como medio para ganarse la vida hasta que pudo entrar al mundo de arte de vanguardia con sus pinturas simbolistas; aquellas que fascinaron a su futuro marido en la visita al estudio de Tanning en 1942. Por esos mismos años se concretaba su colaboración con el coreógrafo Georges Balanchine, desarrollando su actividad como diseñadora de vestuarios y escenografías, hasta que en los años '50 su pintura cambió de forma radical y empezó a producir obras más próximas a la fragmentación y al concretismo. A Tanning no le gustaba presentarse como una abanderada del Surrealismo, que para ella había terminado en los años '50, y decía con frecuencia que su trabajo había cambiado mucho desde entonces y que ser considerada la última surrealista le hacía sentirse como "un fósil". Nada más lejos del espíritu de Tanning, quien en los últimos años de su vida se dedicó sobre todo a la literatura.

¿Por qué entonces, su desaparición ha tenido menos impacto del esperado? ¿Porque era una pintora y no un pintor? En la búsqueda de respuestas a estas preguntas es donde se enmarca la necesidad de analizar la presencia de las mujeres en las instituciones museísticas y ferias de arte entendidos como espacios de cultura. Una reflexión que surge del profundo dilema que provoca que Dorothea Tanning siga ocupando menos páginas en la Historia de las Artes de las merecidas, que las obras de Esther Ferrer salgan al mercado del arte con un precio de tasación muy por debajo de su calidad artística, que sólo tres de los quince Premios Nacionales de Artes Plásticas hayan recaído en mujeres o que las creadoras sólo representen el 31\% de los artistas que integraron ARCO 2012.

Aunque los resultados de los datos de participación de las creadoras en ARCO han mejorado década a década, aún persisten numerosos sesgos de género en la elección de los/as artistas que integran cada una de las ediciones de la feria. La interiorización de una visión androcéntrica del arte limita de manera consciente e inconsciente el alcance de las políticas de adquisición y difusión de obras de arte desde una perspectiva feminista.

La deconstrucción de la epistemología museística y del canon artístico para incorporar la perspectiva de género es un proceso vasto y complejo que los 
museos, galerías y ferias de arte no pueden realizar en solitario. Es una deconstrucción que exige la participación de todos los actores sociales, políticos y educativos y cuyos resultados no son visibles a corto plazo. En lo que respecta a los museos, galerías y ferias de arte, los primeros pasos deben orientarse hacia una reconceptualización de la Historia y las Artes, de las categorías de análisis, del discurso pedagógico y de los puntos de vista de los hechos históricos, artísticos y científicos en los que las mujeres se incorporen como sujetos activos. En la consecución de tales pasos, se proponen a continuación algunas medidas tendentes a favorecer la visibilidad de las mujeres en los museos, galerías y ferias de arte y a implicar a todos los agentes sociales en el reconocimiento del arte creado por las mujeres.

En lo que respecta al fomento de la profesionalización de la gestión y difusión del patrimonio artístico es necesario el cumplimiento de los artículos $26^{18}$ y $35^{19}$ de la Ley de Igualdad de Oportunidades entre mujeres y hombres en la reglamentación de todas las convocatorias de ayudas, becas, subvenciones y concursos de titularidad pública a nivel estatal, autonómico y municipal.

El reconocimiento de las mujeres artistas requiere un proceso amplio de difusión que no discrimine sus aportaciones. Para ello es imprescindible la realización de las medidas tales como el diseño de programaciones específicas de exposiciones retrospectivas que pongan en valor la obra de las artistas, la creación de un archivo que documente la obra de mujeres artistas en la Historia, las Artes y las Ciencias a fin de esclarecer y dignificar su contribución ${ }^{20}$, y la inscripción de estas acciones en una actuación más amplia de fomento de la investigación para

18 Las autoridades públicas, en el ámbito de sus competencias, velarán por hacer efectivo el principio de igualdad de trato y de oportunidades entre mujeres y hombres en todo lo concerniente a la creación y producción artística e intelectual y a la difusión de la misma.

19 Las Administraciones públicas, en los planes estratégicos de subvenciones que adopten en el ejercicio de sus competencias, determinarán los ámbitos en que, por razón de la existencia de una situación de desigualdad de oportunidades entre mujeres y hombres, las bases reguladoras de las correspondientes subvenciones puedan incluir la valoración de actuaciones de efectiva consecución de la igualdad por parte de las entidades solicitantes.

20 Una iniciativa reciente en este sentido ha sido el proyecto "Patrimonio en femenino", una exposición virtual organizada por la Dirección General de Bellas Artes y Bienes Culturales que analiza desde una perspectiva de género la presencia y participación activa de las mujeres a lo largo de la historia, tanto en el ámbito público como privado, a través de un recorrido entre las colecciones de treinta museos españoles integrantes de la Red Digital de Colecciones de Museos de España. Disponible en la dirección web: http://www.mcu.es/novedades/2011/novedades patrimonio femenino.html 
recuperar el legado de las artistas de acuerdo con el Artículo 25 de la Ley de Igualdad $^{21}$.

En lo que respecta a las obras, tanto de autoría masculina como femenina, que representan a mujeres como sujetos artísticos es necesario reformular los discursos pedagógicos. Los carteles que explican la autoría y el significado histórico y/o simbólico de las obras deben incidir en el papel relevante jugado por las mujeres que las crean y/o aparecen en ellas. Por ejemplo, quien visita el MNCARS no sólo encuentra pocas obras creadas por mujeres sino que, además, la información disponible sobre ellas en los discursos expositivos es muy limitada y sesgada. Un ejemplo es la escasa información referente a Dora Maar, cuyas obras se encuentran en las salas 202 y 206.6, que incide fundamentalmente en su vinculación vital y artística con Pablo Picasso invisibilizando así su percepción como una artista independiente con una visión propia del arte.

La deconstrucción de los criterios androcéntricos que determina la entrada de las obras en las colecciones de arte debe afectar también a la gestión y administración de los museos, galerías y ferias donde se observa un notable desequilibrio entre mujeres y hombres. A pesar de que los organigramas de los museos y Centros de Arte de titularidad pública están cubiertos por más del $80 \%$ de profesionales mujeres, este porcentaje se invierte en los órganos de dirección y decisión, tal y como muestra el INFORME MAV 3 presentado en mayo de $2010^{22}$. Por lo tanto, es necesaria la aplicación de un Código de Buenas Prácticas que garantice la imparcialidad y transparencia en los procesos de selección que supere las dificultades derivadas del sistema de cooptación. En este sentido, es necesario desarrollar tres líneas de actuación muy específicas: la inclusión del artículo 26 de la Ley de Igualdad en lo referente a los concursos de cargos en los museos y Centros de Arte de titularidad pública que podría recomendarse desde la Dirección General de Bellas Artes del Ministerio de Cultura; la aplicación de los Artículos $16^{23}$ y $75^{24}$ de la Ley de Igualdad respecto a los patronatos y órganos de decisión;

21 En el ámbito de la educación superior, las Administraciones públicas en el ejercicio de sus respectivas competencias fomentarán la enseñanza y la investigación sobre el significado y alcance de la igualdad entre mujeres y hombres. En particular, y con tal finalidad, las Administraciones públicas promoverán: la inclusión, en los planes de estudio en que proceda, de enseñanzas en materia de igualdad entre mujeres y hombres, la creación de postgrados específicos y la realización de estudios e investigaciones especializadas en la materia.

$22 \mathrm{El}$ pdf del informe está disponible en la siguiente dirección web:

http://www.mav.org.es/index.php?option=com_content\&view=article\&id=288:informemavn3\&catid $=42$ :informes-y-propuestas \&Itemid $=65$

23 Los Poderes Públicos procurarán atender al principio de presencia equilibrada de mujeres y hombres en los nombramientos y designaciones de los cargos de responsabilidad que les correspondan. 
y la incorporación de profesionales especializados en teoría del arte desde una perspectiva de género en los organigramas de Museos y Centros de Arte de titularidad pública a nivel estatal, autonómico y local.

Paralelamente, la difusión de las obras de autoría femenina requiere de una mayor presencia de mujeres en las exposiciones. Para ello el cumplimiento del Artículo 26 de la Ley de Igualdad en la programación de exposiciones de arte contemporáneo en los museos, Centros de Arte y salas de exposiciones de titularidad pública a nivel estatal, autonómico y local y en la gestión del patrimonio de los museos y Centros de Arte constituyen un eje fundamental de actuación.

El escaso porcentaje de mujeres artistas en las galerías de arte supone inevitablemente una menor presencia de sus creaciones en las colecciones públicas y privadas, lo que condiciona la menor visibilidad y valoración tanto artística como económica de sus obras. En consecuencia, es necesario replantear los criterios de adquisición y distribución de las obras. Dada la influencia de las colecciones de titularidad pública en el coleccionismo privado, el cambio decisivo debería darse en primer lugar en el coleccionismo público. La transformación requiere del cumplimiento del Artículo 26 de la Ley de Igualdad en las adquisiciones de museos, galerías, ferias y Centros de Arte de titularidad pública de ámbito estatal, autonómico y local. Esta medida debería verse respaldada por una regulación de los presupuestos de los museos, galerías, ferias y Centros de Arte que destinen partidas específicas y cerradas para adquisiciones de obras de artistas mujeres hasta lograr que las colecciones fuesen paritarias.

Aunque en las galerías y ferias privadas no puede implantarse la obligatoriedad de ninguna acción positiva, las galerías y ferias deben contar con incentivos que hagan atractiva la adquisición de obras de mujeres artistas. Por ejemplo, la creación de ayudas específicas en forma de subvenciones, reducciones o exenciones de impuestos destinadas a favorecer la incorporación de las mujeres artistas en el sistema de galerías de arte.

Finalmente, la difusión de las obras de mujeres entre el gran público requiere la aplicación de las políticas de igualdad en el tratamiento de la información cultural. Sólo la coordinación entre el Ministerio de Cultura y los medios de comunicación de titularidad pública pueden mejorar el tratamiento de los contenidos culturales

24 Las sociedades obligadas a presentar cuenta de pérdidas y ganancias no abreviada procurarán incluir en su Consejo de administración un número de mujeres que permita alcanzar una presencia equilibrada de mujeres y hombres en un plazo de ocho años a partir de la entrada en vigor de esta Ley. Lo previsto en el párrafo anterior se tendrá en cuenta para los nombramientos que se realicen a medida que venza el mandato de los consejeros designados antes de la entrada en vigor de esta Ley. 
de modo que la información sea plural y no exista la discriminación por razón de género en la cobertura informativa. La elaboración de un protocolo de tratamiento de contenidos culturales y de artes visuales conforme a los artículos $36^{25}, 37^{26}$, y $38^{27}$ de la Ley de Igualdad y la incorporación de la perspectiva de género en los organigramas de los departamentos de cultura de los medios de comunicación de titularidad pública contribuirían a que la opinión pública tuviera un acceso objetivo y equitativo a la información de las actividades culturales sin sesgos de género.

La construcción de una sociedad plural requiere de la deconstrucción de los dogmas patriarcales y del desarrollo de nuevas construcciones socioculturales basadas en el derecho a la igualdad y al reconocimiento de los individuos en el pasado y el presente, en el orden real y en el simbólico de la colectividad con independencia del sexo de los individuos. En el contexto artístico, la concreción de dicha deconstrucción reclama nuevas conceptualizaciones que orienten la convergencia reflexiva mediante principios que naturalicen la igualdad y la consiguiente superación de los estereotipos de género que han provocado conductas e identidades excluyentes, androcéntricas y profundamente jerárquicas.

Las galerías, museos y ferias de arte, como centros de ocio y cultura, juegan un papel importante en la interiorización de los valores de equidad e igualdad. La consolidación de una sociedad igualitaria en términos de género requiere que las mujeres sean reconocidas como sujetos activos de la Historia. Es inadmisible que las mujeres no se encuentren en el patrimonio histórico artístico que conservan y difunden las galerías, museos y ferias de arte. Las políticas europeas han reconocido la necesidad de transformar los discursos museísticos desde una perspectiva de género. Sin embargo, la mayoría de los museos españoles no han acometido las recomendaciones que recoge el Séptimo Programa Marco de la Comisión Europea respecto a la visibilización de las mujeres en los centros de arte.

Los datos de ARCO expuestos en el artículo indican que las creaciones artísticas de las mujeres gozan de un reconocimiento inferior al de los hombres. La

25 Los medios de comunicación social de titularidad pública velarán por la transmisión de una imagen igualitaria, plural y no estereotipada de mujeres y hombres en la sociedad, y promoverán el conocimiento y la difusión del principio de igualdad entre mujeres y hombres.

26 La Corporación RTVE, en el ejercicio de su función de servicio público, perseguirá en su programación los siguientes objetivos: reflejar adecuadamente la presencia de las mujeres en los diversos ámbitos de la vida social, utilizar el lenguaje en forma no sexista, adoptar, mediante la autorregulación, códigos de conducta tendentes a transmitir el contenido del principio de igualdad, colaborar con las campañas institucionales dirigidas a fomentar la igualdad entre mujeres y hombres y a erradicar la violencia de género. La Corporación RTVE promoverá la incorporación de las mujeres a puestos de responsabilidad directiva y profesional. Asimismo, fomentará la relación con asociaciones y grupos de mujeres para identificar sus necesidades e intereses en el ámbito de la comunicación.

27 El artículo 38 aplica las medidas del artículo 37 a la Agencia EFE. 
inclusión de las mujeres en las colecciones museísticas, la divulgación de sus creaciones, la revalorización de sus precios de tasación y la deconstrucción de unos criterios artísticos basados en una concepción patriarcal del arte requieren un complejo de redefinición que cuestione los criterios androcéntricos que sustentan la crítica artística. La reivindicación de la autoría femenina y la visibilización de las mujeres en los espacios de cultura es una cuestión de derechos que exige la colaboración de todos los sectores sociales como actores públicos para garantizar un conocimiento plural, crítico y reflexivo en el que las mujeres puedan posicionarse como sujetos activos de la sociedad. Una comunidad en la que los museos, galerías y ferias de arte, centros de ocio y cultura, se conviertan en actores necesarios del cambio social.

\section{BIBLIOGRAFÍA.}

Informes de MAV. Mujeres en las Artes Visuales. http://www.mav.org.es/index.php ALARARIO, T (2008). Arte y feminismo. Madrid, Nerea.

BERNÁRDEZ, A., FERNÁNDEZ, A \& LÓPEZ F. CAO, M (2012): El protagonismo de las mujeres en los museos. Madrid, Fundamentos.

CHADWICK, W. (2002). Women, Art and Society. London, Thames \& Hudson.

COLLADO, A. (2005): Tendencias. Perspectivas feministas en el arte actual. Murcia, Cendeac.

HEARTNEY, E., POSNER, H., PRINCENTHAL, N. \& SCOTT. S (2007). After the revolution: women who transformed contemporary art. Munich, Prestel.

LEVIN, A. (2010). Gender, Sexuality and Museums. Routledge: New York.

LÓPEZ FDEZ. CAO, Marian L. (2010). Mulier me fecit. Hacia un análisis del arte y su educación. Madrid, Horas y Horas.

LÓPEZ FDEZ. CAO, M (2000): Creación artística y mujeres. Recuperar la memoria. Madrid, Narcea.

MAYAYO, P. (2010): “¿Hacia una normalización? El papel de las mujeres en el sistema del arte español", en Juan Antonio Ramírez (ed.). El sistema del arte en España, Cátedra, Madrid, pp. 306-307.

NOCHLIN, L. (1988). "Why Have There Been No Great Women Artists?" Women, Art, and Power and Other Essays. New York, Harper \& Row. pp. 145-178.

PASTOR, María Inmaculada (2004). Pedagogía museística: nuevas perspectivas y tendencias actuales. Barcelona, Ariel.

RECKITT, H (2005): Arte y Feminismo. Londres, Phaidon.

WARNER, M. (1987). Monuments and Maidens. London, Picador.

POLLOCK, G. \& PARKER, R. (1986): Old Mistresses, Woman, Arts and Ideology. London, Pandora Books.

ZIMMERMAN, E. (1981). "Women Also Created Art" Art Education 34.3. Ensor Learning Resource Center. 